\title{
O golpe de 1964 e a ditadura nas pesquisas de opinião
}

\author{
Rodrigo Patto Sá Motta[1]
}

\begin{abstract}
Resumo
$\mathrm{O}$ artigo analisa pesquisas de opinião realizadas pelo Instituto Brasileiro de Opinião Pública e Estatística (IBOPE) no contexto de 1964, com o objetivo de avaliar o apoio ao golpe e à ditadura. Os dados, na maioria inéditos, apontam um contraste entre o apoio a João Goulart, registrado antes do golpe, e os números colhidos depois da vitória golpista, que indicam boa aceitação das medidas autoritárias, inclusive os expurgos políticos. O material empírico resultante das enquetes é utilizado para refletir sobre as fontes de legitimação da ditadura que mobilizaram, sobretudo, representações anticomunistas. A análise dos registros sugere que o apoio ao regime autoritário foi marcado pela instabilidade e oscilou no decorrer dos primeiros anos.
\end{abstract}

Palavras-chave: ditadura; IBOPE; golpe de 1964.

\section{El golpe de 1964 y la dictadura en los sondeos de opinión}

\section{Resumen}

El artículo analiza los sondeos de opinión realizados por el Instituto Brasileño de Opinión Pública y Estadística (IBOPE) en el contexto de 1964, con el objetivo de evaluar el apoyo al golpe y a la dictadura. Los datos, en su mayoría inéditos, señalan un contraste entre el apoyo a João Goulart, apuntado antes del golpe, y los números recogidos después de la victoria golpista, que indican la buena aceptación de medidas autoritarias, incluyendo purgas políticas. El material empírico resultante de los sondeos se utiliza para reflexionar sobre las fuentes de legitimidad de la dictadura, que movilizaron principalmente representantes anticomunistas. El análisis de los registros insinúa que el apoyo al régimen autoritario se caracterizó por la inestabilidad y fluctuó durante los primeros años.

Palabras clave: dictadura; IBOPE; el golpe de 1964.

\section{The 1964 coup and dictatorship in opinion polls}

\begin{abstract}
This article analyzes opinion polls conducted by the Brazilian Institute of Public Opinion and Statistics (IBOPE) in the context of 1964, with the objective of assessing the support to the coup and to dictatorship. The data, mostly new, indicate a contrast between the support to João Goulart, registered before the coup, and after the success of the coup, which points out to the good acceptance of authoritarian measures, including political purges. The empirical data obtained from the polls are used to consider the sources of legitimation of dictatorship that especially mobilized anticommunist representations. The analysis of the records suggests that the support to the authoritarian regime was marked by instability and oscillated throughout the initial years.
\end{abstract}

Keywords: dictatorship; IBOPE; 1964 coup.

\section{Le coup d'État de 1964 et la dictature dans les sondages d'opinion}

\section{Résumé}

Larticle analyse les sondages d’opinion réalisés par l'Institut Brésilien de l'Opinion Publique et des Statistiques (IBOPE) dans le contexte de 1964, dans le but d'évaluer le soutien au coup d'État et à la dictature. Les données, inédites pour la plupart, indiquent un contraste entre le soutien à João Goulart, enregistré avant le coup d'État et les chiffres recueillis après la victoire illicite qui indiquent une bonne acceptation des mesures autoritaires, y compris les épurations politiques. Le matériel empirique originaire des enquêtes est utilisé pour réfléchir sur les sources de légitimation de la dictature qui ont notamment mobilisé les représentations anticommunistes. L' analyse des registres suggère que le soutien au régime autoritaire a été marqué par l'instabilité et a oscillé au cours des premières années.

Mots-clés: dictature; IBOPE; coup d'État de 1964. 
proposta deste artigo é refletir sobre tema polêmico e politicamente delicado, portanto, fundamental: o apoio de segmentos da sociedade brasileira ao golpe de 1964 e à ditadura subsequente. O texto dialoga com a produção historiográfica recente, que contribuiu para (re)colocar o tema em pauta, mas está embasado, sobretudo, em pesquisas de opinião realizadas no calor dos acontecimentos, tanto antes quanto imediatamente após o golpe. Trata-se de fontes interessantes para avaliar o apoio à intervenção autoritária, assim como para analisar os resultados dos esforços para legitimar a ditadura.

$\mathrm{O}$ apoio social à ditadura é assunto candente na historiografia atual que, em parte, tem se inspirado em estudos sobre os estados fascistas europeus e o contexto da ocupação nazista. Nessa direção, têm sido questionadas representações simplistas sobre a ditadura recente que exageram a polarização entre resistentes e colaboradores, como se os dois polos resumissem as opções dos atores da época. Um dos problemas das representações simplificadoras é a tendência a colocar na sombra o apoio de segmentos sociais expressivos ao regime ditatorial, que aderiram de modo espontâneo, sem necessidade de coação. ${ }^{1}$

Para compreender a ditadura, não é suficiente estudar as políticas repressivas e as ações de resistência que elas ensejaram. É necessário também explicar porque parte da sociedade apoiou o autoritarismo e analisar as estratégias utilizadas pelo Estado e seus agentes para alcançar legitimidade. Admitir a existência de apoio à ditadura e que era considerada legítima por segmentos da sociedade é operação analítica arriscada, devido à possibilidade de os argumentos acadêmicos serem manipulados nas disputas políticas pela representação do passado recente. Porém, uma compreensão mais adequada do significado da ditadura vale o risco, inclusive por razões políticas, ou seja, o conhecimento mais acurado poderá contribuir para a superação do autoritarismo, ao contrário da reiteração de representações simplificadoras, embora estas sejam mais confortáveis.

Não obstante a contribuição positiva da nova linha historiográfica, faz-se necessário aprofundar as pesquisas e reflexões, a fim de se evitarem análises simplificadoras em sentido contrário. No caminho da historiografia que enfrenta criticamente a memória do regime autoritário, os riscos a evitar são a superestimação do apoio à ditadura e a subestimação das ações de oposição e de resistência.

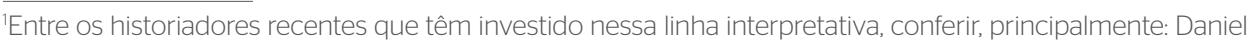
Aarão Reis Filho, Ditadura militar, esquerdas e sociedade, Rio de Janeiro, Zahar, 2000 e Ditadura e democracia no Brasil, Rio de Janeiro, Zahar, 2014; Denise Rollemberg, "Memória, opinião e cultura política: a OAB sob a ditadura", In: Daniel Aarão Reis Filho; Denis Roland (orgs.), Modernidades alternativas, Rio de Janeiro, FGV, 2008, p. 57-96; Denise Rollemberg; Samantha Quadrat, "Introdução", In: A construção social dos regimes autoritários. Legitimidade, consenso e consentimento no século XX. Rio de Janeiro, Civilização Brasileira, 2010, p. 31-44. Registre-se, sobretudo, o trabalho de Daniel Aarão Reis Filho, que serviu como um chamado ao questionamento da memória dominante e um convite a novas pesquisas sobre o apoio social à ditadura. Afirmei que a historiografia recente recolocou a questão em debate porque autores dos anos 1970 e 1980 iniciaram as reflexões sobre o apoio ao golpe e as tentativas de legitimar a ditadura, entre eles, Lúcia Klein, Legitimidade e coação no Brasil pós-64, Rio de Janeiro, Forense Universitária, 1978; René Dreifuss, 1964: a conquista do Estado, 2. ed., Petrópolis, Vozes, 1981; e Maria Helena Moreira Alves, Estado e oposição no Brasil (1964-1984), 4. ed., Bauru, EDUSC, 2005 [1984].
} 
Por outro lado, é importante refletir sobre os conceitos mais adequados para analisar o apoio ao golpe e à ditadura. Parte da literatura acadêmica tem sugerido a aplicação do conceito consenso, que foi utilizado no caso do fascismo para indicar o apoio sólido conquistado pelo regime de Benito Mussolini. No entanto, há divergências sobre o uso de consenso no contexto das ditaduras, já que o conceito é mais utilizado em casos de predomínio de instituições liberal-representativas. É complicado usar a expressão em regimes autoritários, já que não há plena liberdade para criticar os governantes e as vozes de oposição são reprimidas. De acordo com essa linha de interpretação, a existência de consenso só poderia ser comprovada em contextos de liberdade de expressão, ou seja, ele teria que ser expresso livremente. ${ }^{2}$

\section{O medo de ameaças à ordem foi ingrediente central na crise política de 1964 e expressou-se, sobretudo, por meio do imaginário anticomunista}

Além das dificuldades conceituais, há outras razões para considerar que a suposição de consenso a favor da ditadura no Brasil não é a melhor opção analítica. Os resultados das pesquisas de opinião permitem pensar a questão em outros termos, como se verá. Além de debater quais os conceitos adequados para expressar a realidade do apoio social à ditadura, o desafio maior é entender por que alguns grupos aceitaram a intervenção autoritária como opção política legítima e, também, mensurar e mapear os setores da sociedade influenciados pela opinião favorável ao golpe e à ditadura. As informações analisadas a seguir comprovam o apoio à ditadura e oferecem uma expressão numérica desse fenômeno. Porém, ao mesmo tempo, apontam para nuanças que é preciso considerar nas reflexões sobre o apoio social ao regime autoritário. Como será mostrado, uma proporção elevada de cidadãos deu suporte ao golpe e aos expurgos políticos; entretanto, o estabelecimento de uma ditadura sob tutela militar não atraiu o mesmo entusiasmo.

Os dados analisados a seguir foram retirados de pesquisas realizadas pelo Instituto Brasileiro de Opinião Pública e Estatística (IBOPE) no contexto do golpe de 1964. Algumas dessas enquetes começaram a ser utilizadas por cientistas sociais e historiadores no início dos anos 1990, pouco após o IBOPE ter doado seu acervo ao Arquivo Edgard Leuenroth (AEL). Parte do material foi

\footnotetext{
${ }^{2}$ Alguns autores duvidam da utilidade do conceito mesmo para regimes liberal-representativos, pois a expressão faria perder-se a dimensão das fraturas e dissensos. Para as discussões sobre consenso em regimes fascistas e autoritários, ver a coletânea organizada por Denise Rollemberg; Samantha Quadrat, $A$ construção social dos regimes autoritários. Legitimidade, consenso e consentimento no século XX. Rio de Janeiro, Civilização Brasileira, 2010, especialmente o texto introdutório das organizadoras e o capítulo de Patrizia Dogliani. No caso brasileiro, poder-se-ia dizer que as eleições periodicamente vencidas pelos líderes da ditadura seriam um sintoma de apoio consensual. No entanto, nunca houve quadro de total liberdade (cassações, prisões, casuísmos eleitorais) e, mesmo assim, a oposição obteve vitórias importantes em certos pleitos, como em 1965 e 1974.
} 
analisada pela historiografia mais recente; ${ }^{3}$ no entanto, a maioria das pesquisas de opinião mostradas a seguir permanecia inédita.

Antes de entrar na análise das enquetes, é preciso ressalvar a necessidade de cuidados críticos na sua utilização. De um lado, porque podem revelar apenas opiniões momentâneas dos entrevistados, cujas respostas, ademais, podem ser induzidas a depender do modo como são elaborados os questionários. Além disso, em certas circunstâncias, o interesse de fazer uso político dos resultados gera manipulações e falsificações. Por outro lado, no caso brasileiro, há que estudar melhor os fenômenos de opinião, pois há indícios de que a opinião política dos cidadãos nem sempre primava pela solidez. O contraste entre algumas enquetes mostra resultados conflitantes que, em certos casos, sugerem a ocorrência de mudanças bruscas de opinião. Ademais, é sempre elevada a proporção de abstenções, ou seja, das pessoas que preferem não responder, ou que optam por "não sei" ou "não opina". Trata-se de indício da existência de muitos cidadãos com opinião política superficial, desinformados ou desinteressados. Outro limite é o fato de as pesquisas restringirem-se a algumas cidades, em geral, São Paulo ou Rio de Janeiro. Nessa série, não há enquetes realizadas em âmbito nacional, que eram raras naqueles anos. A pesquisa mais ampla envolveu a capital paulista e duas cidades do interior, Araraquara e Avaí, provavelmente para oferecer elementos de comparação e projetar qual seria a opinião em todo o Estado de São Paulo.

Apesar das ressalvas e dos cuidados necessários, há circunstâncias que atenuam o ceticismo e levam a crer na utilidade desses registros como fontes de informação. Em primeiro lugar, aparentemente, as pesquisas não se destinavam à publicação, o que reduz o interesse em manipular a opinião dos cidadãos. O objetivo dos financiadores das pesquisas provavelmente era obter dados para planejar ações políticas e avaliar os resultados de certas campanhas de propaganda. Em alguns casos, devido ao perfil das questões aplicadas, temse a impressão de que foram encomendadas pelo governo militar para avaliar a recepção da sociedade a suas políticas. Não há registro de que tenham sido publicadas à época da sua realização; ${ }^{4}$ por isso, teriam permanecido desconhecidas até recentemente, adormecidas nos arquivos. Por fim, o fato de as

\footnotetext{
${ }^{3}$ A doação do IBOPE ao AEL ocorreu em 1989. O pesquisador pioneiro na utilização do acervo foi Antônio Lavareda (A democracia nas urnas, Rio de Janeiro, Rio Fundo; IUPERJ, 1991). Em obras recentes dedicadas ao golpe e à ditadura, os historiadores Marcos Napolitano (1964: história do Regime Militar Brasileiro, São Paulo, Contexto, 2014) e Jorge Ferreira; Angela de Castro Gomes (1964: o golpe que derrubou um presidente, pôs fim ao regime democrático e instituiu a ditadura no Brasil, Rio de Janeiro, Civilização Brasileira, 2014) também lançaram mão de algumas pesquisas do IBOPE.

${ }^{4}$ Segundo Antônio Lavareda, op cit., p. 123, que investigou as pesquisas do IBOPE dos anos 1950 e 1960, os jornais tinham pouco interesse pelos levantamentos de opinião, e os principais clientes do instituto eram políticos e empresários. Não foi possível encontrar informações sobre quem encomendou as pesquisas e tampouco que tenham sido publicadas à época. Em algumas enquetes, está registrado "IBOPE FECIT", o que pode significar apenas "o IBOPE fez", em uma tradução livre do latim fecit. Todas as pesquisas do IBOPE citadas neste texto estão arquivadas no AEL. No acervo documental doado pelo IBOPE, encontramse pesquisas de variado tipo e não apenas enquetes políticas: há levantamentos sobre consumo, audiência de programas de TV e rádio, publicidade e propaganda, hábitos de leitura, entre outros. Outros comentários e informações sobre as técnicas e metodologias das pesquisas serão apresentados em notas de rodapé adiante.
} 
pesquisas restringirem-se a algumas cidades não reduz sua representatividade, pois se tratava das metrópoles mais importantes do país, com capacidade de influenciar áreas mais amplas, e a comparação entre os resultados colhidos nas metrópoles revela uma forte congruência nas opiniões.

Outro argumento favorável ao ceticismo foi apresentado por colegas durante eventos em que essas pesquisas foram apresentadas. Eles questionaram a validade das enquetes posteriores ao golpe, sugerindo que os entrevistados evitariam falar a verdade por temor à repressão. $\mathrm{O}$ argumento é pouco convincente por duas razões principais: as entrevistas eram anônimas, sendo difícil imaginar que os entrevistados se sentissem ameaçados; e, mais importante, algumas pesquisas revelaram resultados contrários aos interesses da ditadura também, o que evidencia a disposição em dar respostas negativas ao Estado caso desejassem.

Os relatórios do IBOPE oferecem várias possibilidades analíticas interessantes, já que algumas enquetes foram estratificadas por níveis de renda e por sexo. ${ }^{5}$ Diante da dificuldade de explorar todas as possibilidades no limite de um artigo, a opção foi trabalhar apenas com os resultados principais. $\mathrm{O}$ objetivo é dimensionar a proporção dos que apoiaram o golpe e avaliar a sua motivação para fazê-lo. Além disso, especular se os militares teriam sustentação para uma ditadura "clássica", ou seja, que cancelasse todas as instituições liberais e afirmasse uma opção autoritária mais explícita.

\section{As pesquisas anteriores ao golpe}

Na análise das pesquisas, um dos maiores desafios é entender as oscilações - e o contraste - entre atitudes de apoio a João Goulart (Jango) e de concordância com a sua derrubada. Pesquisas realizadas alguns dias antes do golpe de 1964 mostram índices significativos de apoio a Goulart. No entanto, outras enquetes realizadas pelo IBOPE cerca de dois meses depois revelam apoio notável ao golpe. Como entender o paradoxo?

Vejamos primeiro as pesquisas que apontam a popularidade de Goulart e o apoio ao projeto das "reformas de base". Segundo esses dados, Jango era bem visto por segmentos sociais expressivos e gozava de boa popularidade. Quanto às reformas de base, sobretudo a agrária, elas atraíam maior apoio ainda da sociedade (com uma exceção, a ser mostrada adiante), sendo mais populares que Goulart. Seguem alguns dados de uma das pesquisas mais completas encontradas no acervo, realizada nas cidades de São Paulo, Araraquara e Avaí entre os dias 20 e 30 de março de 1964. Comecemos com a avaliação sobre o governo Goulart (Tabela 1).

\footnotetext{
${ }_{5}^{5}$ Embora não haja espaço para aprofundar a análise, podem ser apontadas algumas impressões colhidas na leitura do material: maior índice de abstenções entre as camadas mais pobres e adesão mais forte aos argumentos conservadores (em geral, anticomunistas) entre os mais ricos e as mulheres. Mais sobre isso adiante. Ainda sobre a metodologia adotada, o IBOPE registrava que a representatividade da amostragem baseava-se em estratificação por sexo, por perfis socioeconômicos e por distribuição geográfica. As amostras circulavam em torno de 500 entrevistados em cada cidade. O tamanho da amostra e os critérios de distribuição são próximos aos utilizados nos dias de hoje.
} 
Tabela 1. Pesquisa do Instituto Brasileiro de Opinião Pública e Estatística (IBOPE) realizada entre 20 e 30 de março de 1964, com base em 950 entrevistas

\begin{tabular}{lcccccc}
$\begin{array}{l}\text { Como o sr(a) considera o } \\
\text { Governo João Goulart, até agora? }\end{array}$ & Ótimo & Bom & Regular & Mau & Péssimo & $\begin{array}{c}\text { Não } \\
\text { sabem }\end{array}$ \\
\hline São Paulo & $13 \%$ & $29 \%$ & $30 \%$ & $7 \%$ & $12 \%$ & $9 \%$ \\
\hline Araraquara & $15 \%$ & $24 \%$ & $23 \%$ & $10 \%$ & $11 \%$ & $17 \%$ \\
\hline Avaí & $18 \%$ & $37 \%$ & $19 \%$ & $5 \%$ & $5 \%$ & $16 \%$ \\
\hline
\end{tabular}

Fonte: Arquivo Edgard Leuenroth.

Existem pesquisas semelhantes realizadas em outras cidades brasileiras, com resultados ora mais positivos, ora mais negativos para Goulart, mas essa enquete é interessante por permitir a comparação entre uma metrópole e dois municípios do interior. O resultado revela pouca variação nas opiniões manifestadas em cada cidade, exceto por um índice maior de não respondentes nos municípios menores e uma popularidade maior para Goulart em Avaí. Considerando apenas São Paulo, o governo Jango era visto como ótimo/bom por $42 \%$, regular por $30 \%$ e mau/péssimo por apenas $19 \%$. Os dados mostram que, às vésperas da sua deposição, o presidente tinha imagem relativamente positiva entre os paulistanos.

Aspecto importante é que a enquete procurou verificar a repercussão do comício de 13 de março de 1964, realizado na Guanabara (Rio de Janeiro), o qual marcou o engajamento mais intenso do presidente em favor da realização de reformas. No entanto, o IBOPE não fez perguntas relacionadas ao evento de 19 de março em São Paulo, a chamada Marcha da Família com Deus pela Liberdade, que representou grande mobilização liberal-conservadora em resposta ao comício de 13 de março. Talvez o material da pesquisa já estivesse pronto e não foi possível incorporar o novo evento; de qualquer modo, os entrevistados já estavam sob o impacto da Marcha.

Os dados mostram que o apoio a Goulart continuou elevado e que a grande maioria permanecia favorável às reformas. No entanto, como se verá também, a pesquisa apontou notável repúdio ao comunismo e, mais ainda, registrou a sensação de que o "perigo vermelho" estava crescendo, exatamente o tema principal da campanha da direita. Voltaremos a isso adiante - primeiro, a opinião sobre as reformas.

Várias pesquisas de opinião da época mostram alto índice de apoio às chamadas reformas de base e esses dados são conhecidos há mais tempo. ${ }^{6}$ As enquetes mostram que o repúdio total a reformas, o que poderia ser chamado de antirreformismo, era postura com fraco apelo na opinião pública. ${ }^{7}$ Na pesquisa realizada nas três cidades paulistas, o tema foi bastante explorado (Tabela 2).

“Especialmente os dados sobre reforma agrária. Cf. Antônio Lavareda, A democracia nas urnas, Rio de Janeiro: Rio Fundo/IUPERJ, 1991, p. 157.

${ }^{7}$ Naturalmente, não se entende a opinião pública como estanque e singular; ao contrário, o melhor seria falar em opiniões para dar conta de fenômeno tão complexo. A esse respeito, ver Jean-Jacques Becker, "A opinião pública", In: René Rémond (org.), Por uma história política, 2. ed., Rio de Janeiro, FGV, 2003, p. 185-211. 
Tabela 2. Pesquisa do Instituto Brasileiro de Opinião Pública e Estatística (IBOPE) realizada entre 20 e 30 de março de 1964, com base em 950 entrevistas

\begin{tabular}{lcccc}
$\begin{array}{l}\text { Em relação às reformas } \\
\text { de base desejadas pelo } \\
\text { presidente João Goulart, } \\
\text { o sr (a) acha que elas são: }\end{array}$ & $\begin{array}{c}\text { Absolutamente } \\
\text { necessárias, e } \\
\text { com urgência }\end{array}$ & $\begin{array}{c}\text { Necessárias, } \\
\text { porém com } \\
\text { moderação, sem } \\
\text { pressa }\end{array}$ & $\begin{array}{c}\text { Não são } \\
\text { necessárias }\end{array}$ & $\begin{array}{c}\text { Não } \\
\text { sabem }\end{array}$ \\
São Paulo & $40 \%$ & $39 \%$ & $7 \%$ & $14 \%$ \\
Araraquara & $39 \%$ & $24 \%$ & $7 \%$ & $30 \%$ \\
\hline Avaí & $52 \%$ & $17 \%$ & $6 \%$ & $25 \%$ \\
\hline
\end{tabular}

Fonte: Arquivo Edgard Leuenroth.

Sem considerar as pequenas diferenças nas respostas encontradas nas três cidades, o mais importante é registrar o elevado nível de apoio à demanda por reformas. O percentual de pessoas que as achavam desnecessárias era muito pequeno e a opinião favorável à urgência nas reformas ficou em torno de $40 \%$. Outras pesquisas convergem com esses dados, especialmente enquetes sobre a reforma agrária, que revelam índice de apoio em torno de $70 \%$ em média nos levantamentos realizados em várias capitais brasileiras. ${ }^{8}$

\section{Muitos cidadãos apoiavam reformas e tinham boa impressão do governo Goulart, porém repudiavam alternativas de esquerda mais radicais}

No entanto, uma das reformas políticas pretendidas não alcançava o mesmo apoio e dividia mais as opiniões: a proposta de estender o direito de voto aos analfabetos. Na mesma pesquisa, perguntou-se aos entrevistados de São Paulo, Araraquara e Avaí se eram a favor dessa medida, que tinha grande respaldo entre as esquerdas. $\mathrm{O}$ resultado foi bem diferente em relação à postura sobre as outras reformas, pois $49 \%$ dos paulistanos responderam que discordavam do voto para os analfabetos, contra $46 \%$ a favor. Pesquisas semelhantes em outras regiões do país mostraram igual (ou maior) rejeição ao direito de voto para analfabetos: em Minas Gerais, em setembro de 1963, 76\% responderam não à proposta contra apenas $23 \%$ favoráveis; na Guanabara, em outubro de 1963, 55\% dos eleitores mostraram-se contrários ao voto para os analfabetos, contra $43 \%$ a favor.

Na análise desses dados, uma das conclusões possíveis é que a opinião era majoritariamente reformista quando as mudanças afetariam o interesse de poucos, como no caso da distribuição de terras, que atingiria apenas os grandes proprietários. Porém, no caso do voto dos analfabetos, a proposta tocava em interesses e temores mais amplos, já que a inclusão no sistema eleitoral de

${ }^{8} \mathrm{Cf}$. Jorge Ferreira; Angela de Castro Gomes, 1964: o golpe que derrubou um presidente, pôs fim ao regime democrático e instituiu a ditadura no Brasil, Rio de Janeiro, Civilização Brasileira, 2014, p. 295. 
uma massa enorme de pobres e excluídos poderia mudar a balança política em favor da esquerda, ou dos "demagogos", tal como denunciava a opinião de direita. É interessante que outro ponto da reforma política, o direito dos subalternos das Forças Armadas votarem e serem eleitos, atraía o apoio da maioria dos entrevistados. Embora fosse uma questão politicamente explosiva, pois desagradava à direita e dividia os meios castrenses, a eleição dos militares subalternos não assustava a maioria da opinião pública. ${ }^{9}$ Mas o voto dos analfabetos sim. Esse contraste revela que número elevado de pessoas aceitaria mudanças sociais moderadas, porém, ao mesmo tempo, a maioria delas temia a possibilidade de transformações mais agudas.

O medo de ameaças à ordem foi ingrediente central na crise política de 1964 e expressou-se, sobretudo, por meio do imaginário anticomunista. ${ }^{10}$ Mobilizações anticomunistas faziam parte do repertório do Estado e de grupos de direita desde o início do século, mas, entre 1961-1964, elas alcançaram picos elevados, graças à combinação de fatores internos (incremento nas reivindicações e protestos sociais) e externos (Guerra Fria, revoluções no Terceiro Mundo). Na derrubada de Goulart, em 1964, as representações anticomunistas tiveram um papel-chave, que as enquetes nos permitirão compreender melhor. Vejamos alguns exemplos nas Tabelas 3 e 4.

A pesquisa mediu a opinião dos cariocas sobre um dos eventos que polarizou a esquerda e a direita no ano de 1963. Tratou-se da tentativa de realizar um Congresso de Solidariedade a Cuba na Guanabara, naturalmente, organizado por grupos de esquerda. A realização do evento na Guanabara foi proibida pelo governador e destacado líder anticomunista Carlos Lacerda, gerando uma celeuma de âmbito nacional. Os resultados da pesquisa mostram que a grande maioria (63\%) dos cariocas apoiou o ato do governador e que um número pouco menor, mas, ainda assim elevado (49\%), concordou com a afirmação de que o evento ameaçaria as instituições democráticas e a segurança nacional.

Outras enquetes mostram o afloramento da sensibilidade anticomunista. Em fevereiro de 1964, em pesquisa que explorou vários temas políticos, o IBOPE perguntou o seguinte para eleitores de São Paulo: "considera que o comunismo está aumentando ou diminuindo?" O resultado é que $54 \%$ responderam "aumentando" e 16\%, "diminuindo", enquanto $28 \%$ não tinham opinião. O mais interessante foi a pergunta seguinte, aplicada somente aos $54 \%$ que responderam que o comunismo estaria aumentado, uma questão provavelmente planejada para dimensionar o tamanho da opinião anticomunista e distinguir a porcentagem de simpatizantes da esquerda. A pergunta era se o comunismo representava um perigo ou não e $81 \%$ responderam que sim, contra $13 \%$ que disseram não. Fazendo uma aritmética simples, o resultado é que, às vésperas do golpe, $44 \%$ dos paulistanos ( $81 \%$ de $54 \%$ ) viam no comunismo um perigo.

\footnotetext{
${ }^{9}$ Em outra pesquisa na Guanabara (junho de 1964), em que a maioria dos entrevistados foi contra o voto para os analfabetos, $76 \%$ responderam a favor do voto para os sargentos.

${ }^{10} \mathrm{Cf}$. Rodrigo Patto Sá Motta, Em guarda contra o perigo vermelho: o anticomunismo no Brasil (1917-1964), São Paulo, Perspectiva; FAPESP, 2002.
} 
Tabela 3. Pesquisa do Instituto Brasileiro de Opinião Pública e Estatística (IBOPE) na Guanabara (Rio de Janeiro), entre 29 e 31 de março de 1963, com base em 511 entrevistas

\begin{tabular}{lllc}
$\begin{array}{l}\text { O governador Lacerda agiu bem ao proibir o } \\
\text { Congresso de solidariedade a Cuba? }\end{array}$ & Sim & Não & $\begin{array}{c}\text { Não sabem/ } \\
\text { não opinam }\end{array}$ \\
\hline & $63 \%$ & $19 \%$ & $18 \%$
\end{tabular}

Fonte: Arquivo Edgard Leuenroth.

Tabela 4. Pesquisa do Instituto Brasileiro de Opinião Pública e Estatística (IBOPE) na Guanabara (Rio de Janeiro), entre 29 e 31 de março de 1963, com base em 511 entrevistas A realização desse Congresso representa uma ameaça para a Segurança Nacional e para as instituições democráticas?

Sim Não

$49 \%$
Não sabem/ não opinam

Fonte: Arquivo Edgard Leuenroth.

Voltando à pesquisa realizada em março de 1964 nas cidades de São Paulo, Araraquara e Avaí, a mesma que apontou $42 \%$ de opiniões favoráveis ao governo Goulart e elevado índice de apoio às reformas de base, encontramos registros importantes sobre o repúdio à esquerda. Por exemplo, uma das perguntas abordou a legalização do Partido Comunista Brasileiro (PCB), medida que estaria sendo cogitada pelo governo Goulart. Na maioria, as forças de direita eram contrárias à proposta, não obstante alguns líderes preferissem legalizar o partido para melhor controlar suas atividades. A enquete revelou que $80 \%$ dos entrevistados paulistanos eram contrários à legalização do PCB, contra apenas $13 \%$ favoráveis. Embora os dados não permitam concluir que todos os contrários à legalização esposavam valores anticomunistas sólidos, eles são certamente um indicador nessa direção. Vale a pena reproduzir o resultado de outra pergunta elaborada pelo IBOPE para medir a opinião anticomunista (Tabela 5).

Importante notar - e o comentário vale também para enquetes mostradas anteriormente - que a construção da pergunta revela o vínculo com o imaginário anticomunista, pois o uso do termo "perigo" já denota uma condenação. Com isso, a pesquisa contribui para influenciar a opinião política dos entrevistados. No entanto, havia a possibilidade de negar o discurso anticomunista optando pela terceira resposta ("não é um perigo").

Os resultados nos três municípios foram basicamente convergentes, exceto pelo número maior de abstenções no interior. Considerando os dados para São Paulo, $32 \%$ responderam que o perigo era imediato e outros $36 \%$ que o perigo era futuro, totalizando $68 \%$ os quais escolheram referir-se ao comunismo como um perigo. Nos outros dois municípios, esse número também foi superior a $60 \%$. Os dados indicam o impacto significativo das campanhas anticomunistas, bem como aumento da percepção sobre a presença do comunismo no cenário público se compararmos com os resultados da pesquisa de fevereiro de 1964. Mais ainda, as pesquisas sugerem o potencial apoio de setores sociais 
Tabela 5. Pesquisa do Instituto Brasileiro de Opinião Pública e Estatística (IBOPE) realizada entre 20 e 30 de março de 1964, com base em 950 entrevistas

\begin{tabular}{lcccc}
$\begin{array}{l}\text { O sr (a) acha que o comunismo } \\
\text { para o Brasil representa: }\end{array}$ & $\begin{array}{c}\text { Um perigo } \\
\text { imediato }\end{array}$ & $\begin{array}{c}\text { Um perigo } \\
\text { futuro }\end{array}$ & $\begin{array}{c}\text { Não é um } \\
\text { perigo }\end{array}$ & Não sabe \\
\hline São Paulo & $32 \%$ & $36 \%$ & $19 \%$ & $13 \%$ \\
\hline Araraquara & $37 \%$ & $26 \%$ & $15 \%$ & $22 \%$ \\
Avaí & $37 \%$ & $24 \%$ & $9 \%$ & $30 \%$ \\
\hline
\end{tabular}

Fonte: Arquivo Edgard Leuenroth.

expressivos a políticas antiesquerdistas. Como se verá na próxima seção, após o golpe, foi elevado o número de cidadãos que apoiou o expurgo das esquerdas.

Observação importante: não se deve confundir a sensibilidade anticomunista e o temor a ameaças à ordem social com as avaliações sobre o governo Goulart. A pesquisa realizada nas três cidades paulistas bem como enquetes feitas em outras cidades brasileiras mostram que a simpatia por reformas e por Goulart conviviam com valores anticomunistas. Em outras palavras, muitos cidadãos apoiavam reformas e tinham boa impressão do governo Goulart, porém repudiavam alternativas de esquerda mais radicais. Além disso, somente a minoria associava diretamente Goulart ao "perigo comunista", o que pode ser visto nos resultados de outra pergunta aplicada na mesma pesquisa (Tabela 6).

\section{As pesquisas a partir de maio de 1964 apontam uma guinada na opinião, com a maioria mostrando-se concorde com a derrubada de Goulart e favorável aos expurgos políticos}

A pergunta se refere às medidas anunciadas por Goulart no comício da Central do Brasil, que marcou a guinada do governo na direção de política reformista mais incisiva. As lideranças conservadoras perceberam o evento como uma guinada esquerdista do presidente e responderam com a Marcha com Deus, em São Paulo, e o incremento de articulações golpistas em várias partes do país. Porém, a pesquisa realizada pelo IBOPE entre 20 e 30 de março mostra elevado índice de confiança nos objetivos reformistas do presidente, com mais de $50 \%$ de respostas favoráveis ( $55 \%$ na capital paulista). As opiniões contrárias a Goulart restringiram-se a $26 \%$ em São Paulo, sendo que apenas $16 \%$ associaram o comício da Central a uma suposta ofensiva comunista.

Poucos dias antes do golpe que derrubaria Goulart, a pesquisa do IBOPE mostra que cerca de metade do eleitorado (paulista) confiava nas intenções do presidente, enquanto apenas um quarto mostrava-se sensível ao discurso oposicionista. No entanto, vale reiterar, o apoio potencial para campanhas anticomunistas era grande e, caso as forças de oposição conseguissem "colar" a imagem de Goulart ao "perigo comunista”, os efeitos políticos seriam marcantes. 
Tabela 6. Pesquisa do Instituto Brasileiro de Opinião Pública e Estatística (IBOPE)

realizada entre 20 e 30 de março de 1964, com base em 950 entrevistas

\begin{tabular}{lcccc}
$\begin{array}{l}\text { Qual destes modos } \\
\text { de pensar está mais } \\
\text { de acordo com sua } \\
\text { opinião sobre estas } \\
\text { últimas medidas } \\
\text { do presidente João } \\
\text { Goulart: }\end{array}$ & $\begin{array}{c}\text { São medidas } \\
\text { demagógicas, } \\
\text { que procuram } \\
\text { oprestígio do } \\
\text { Sr. João Goulart e } \\
\text { do PTB }\end{array}$ & $\begin{array}{c}\text { São medidas } \\
\text { de real } \\
\text { interesse } \\
\text { para o povo e } \\
\text { para o país }\end{array}$ & $\begin{array}{c}\text { São medidas que } \\
\text { procuram criar } \\
\text { condições para o } \\
\text { estabelecimento } \\
\text { de um regime } \\
\text { comunista no } \\
\text { Brasil }\end{array}$ & $\begin{array}{c}\text { Não } \\
\text { sabem }\end{array}$ \\
São Paulo & $10 \%$ & $55 \%$ & $16 \%$ & $19 \%$ \\
Araraquara & $10 \%$ & $47 \%$ & $16 \%$ & $27 \%$ \\
\hline Avaí & $8 \%$ & $53 \%$ & $8 \%$ & $31 \%$ \\
\hline
\end{tabular}

Fonte: Arquivo Edgard Leuenroth.

\section{As enquetes de opinião após o golpe}

No acervo do IBOPE, a pesquisa posterior ao golpe mais próxima dos eventos foi realizada entre 12 e 22 de maio de 1964, na cidade de São Paulo. Os resultados dessa enquete - assim como de outras que serão mostradas adiante - implicam grande desafio analítico, pois revelam paradoxo na comparação com a pesquisa do fim de março de 1964. Naquela enquete, como se viu, o eleitorado parecia relativamente confiante com o governo Goulart, ao menos no que toca às propostas de reformas de base. Porém, as pesquisas a partir de maio de 1964 apontam uma guinada na opinião, com a maioria mostrando-se concorde com a derrubada de Goulart e favorável aos expurgos políticos, notadamente quando os alvos eram de esquerda (Tabelas 7 e 8).

De acordo com os números apresentados, aproximadamente um mês e meio após o golpe, a maioria do eleitorado paulista via com bons olhos a nova situação política e tinha expectativas positivas para o futuro. O mais marcante é que $54 \%$ dos paulistanos consideraram benéfica a derrubada de Goulart, enquanto dois meses antes, no fim de março, $42 \%$ achavam o governo dele bom ou ótimo e apenas 19\% o viam como mau ou péssimo (e 30\% o avaliaram como regular). Como explicar essa aparente virada de opinião em período tão curto? Mudanças de opinião no eleitorado ocorreram com frequência e, como se verá, a avaliação do primeiro governo militar mudou bastante entre 1964 e 1965. O que chama atenção é a rapidez maior do processo nesse caso.

Primeiramente, é preciso considerar que os $54 \%$ que aprovaram a deposição de Goulart representam maioria apertada, pouco mais da metade do eleitorado paulista. Isso significa que o número dos que mudaram de opinião talvez não tenha sido tão grande. Fazendo um exercício hipotético, poderíamos supor que os $30 \%$ que achavam Jango regular se uniram à opinião dos $19 \%$ os quais tinham avaliação negativa e que uma parte dos simpatizantes do governo mudou de opinião no momento do golpe. Outra hipótese a considerar é que a pesquisa do fim de março de 1964 pode não ter medido o impacto do agravamento da crise, sobretudo o episódio dos marinheiros na Guanabara, 
Tabela 7. Pesquisa do Instituto Brasileiro de Opinião Pública e Estatística (IBOPE) realizada entre 12 e 22 de maio de 1964, em São Paulo, com base em 500 entrevistas

\begin{tabular}{lccc}
$\begin{array}{l}\text { Na sua opinião, a deposição do presidente } \\
\text { Goulart constituiu uma medida benéfica ou } \\
\text { prejudicial para o país? }\end{array}$ & $\begin{array}{c}\text { Benéfica } \\
\text { Prejudicial }\end{array}$ & $\begin{array}{c}\text { Não } \\
\text { sabem }\end{array}$ \\
\hline
\end{tabular}

Fonte: Arquivo Edgard Leuenroth

Tabela 8. Pesquisa do Instituto Brasileiro de Opinião Pública e Estatística (IBOPE) realizada entre 12 e 22 de maio de 1964, em São Paulo, com base em 500 entrevistas

\begin{tabular}{lcccc}
$\begin{array}{l}\text { Na sua opinião, a situação do Brasil } \\
\text { agora tende a melhorar ou a piorar? }\end{array}$ & Melhorar & Piorar & $\begin{array}{c}\text { Ficar } \\
\text { igual }\end{array}$ & $\begin{array}{c}\text { Não } \\
\text { sabem }\end{array}$ \\
\hline
\end{tabular}

Fonte: Arquivo Edgard Leuenroth.

em 25 e 26 de março, o qual teve influência marcante na desestabilização do governo Goulart.

Além disso, é preciso considerar a influência do golpe bem-sucedido sobre a opinião dos cidadãos. Os vitoriosos lançaram uma campanha discursiva para convencer que sua ação foi necessária no interesse da maioria. Nesse sentido, a imprensa mais engajada no golpe - a exemplo dos influentes O Globo e O Estado de S. Paulo - empenhou-se a fundo na defesa do "31 de março" e na crítica ao governo deposto e seus aliados de esquerda. Não se trata de supervalorizar a influência da mídia no tocante ao apoio ao regime militar, afinal, os valores que justificaram o golpe já faziam parte do cenário político; ademais, alguns veículos da imprensa que apoiaram a derrubada de Goulart logo se afastaram da opinião golpista e começaram a criticar as ações repressivas do novo governo. Ainda assim, os discursos favoráveis ao golpe predominaram na mídia nas primeiras semanas e devem ter contribuído para mudar a opinião de parte dos cidadãos.

Outra pergunta aplicada na mesma pesquisa (maio de 1964) permite avaliar a influência dos discursos golpistas e confirma o alto percentual de paulistanos favoráveis à derrubada de Goulart (Tabela 9).

As opções oferecidas aos entrevistados condensavam os principais argumentos presentes no debate político, sendo que a segunda pergunta, que atraiu apenas $17 \%$ das respostas, representava a visão dominante à esquerda. A primeira e a terceira opção correspondiam às visões golpistas e, juntas, somaram $55 \%$ das respostas, número quase idêntico aos $54 \%$ que consideraram benéfica a deposição de Goulart. Significativamente, a opção que atraiu mais respostas (34\%) associava a motivação golpista à luta contra o "comunismo", ou seja, Goulart teria sido derrubado porque seu governo poderia conduzir o país para o comunismo. Esse resultado contrasta bastante com os $16 \%$ apenas que, em março de 1964, responderam que o plano reformista de Goulart tinha intenções comunistas. Não é necessário repetir a análise feita há pouco sobre a 
Tabela 9. Pesquisa do Instituto Brasileiro de Opinião Pública e Estatística (IBOPE) realizada entre 12 e 22 de maio de 1964, em São Paulo, com base em 500 entrevistas

\begin{tabular}{|c|c|c|c|c|}
\hline $\begin{array}{l}\text { A qual destas } \\
\text { razões o Sr (a) } \\
\text { atribui a queda } \\
\text { do presidente } \\
\text { João Goulart? }\end{array}$ & $\begin{array}{l}\text { Estava } \\
\text { levando o } \\
\text { Brasil para } \\
\text { um regime } \\
\text { comunista }\end{array}$ & $\begin{array}{l}\text { Estava tomando } \\
\text { medidas populares } \\
\text { que contrariavam } \\
\text { fortes interesses de } \\
\text { grupos econômicos e } \\
\text { financeiros, nacionais } \\
\text { e estrangeiros }\end{array}$ & $\begin{array}{c}\text { Pretendia } \\
\text { fechar o } \\
\text { Congresso } \\
\text { (Câmara e } \\
\text { Senado) para se } \\
\text { tornar Ditador }\end{array}$ & $\begin{array}{c}\text { Não } \\
\text { sabem }\end{array}$ \\
\hline & $34 \%$ & $17 \%$ & 21\% & $28 \%$ \\
\hline
\end{tabular}

Fonte: Arquivo Edgard Leuenroth.

possibilidade de mudanças de opinião. Mas vale a pena reiterar que o temor anticomunista esteve sempre presente no cenário e os números de maio de 1964 indicam que a imagem de Goulart foi efetivamente associada ao perigo vermelho, tornando justificável o golpe na visão de muitas pessoas.

É interessante analisar os dados dessa pesquisa considerando-se a estratificação social dos entrevistados, que foram divididos pelo IBOPE em classe A-B (rica e média), C (pobre) e D (pobre inferior). Os dados confirmam algo que observadores contemporâneos apontaram na época: as camadas superiores receberam com mais entusiasmo o golpe. Na camada $A-B$, o número de abstenções foi menor e as respostas concordes com a opinião golpista ascenderam a $67 \%$, sendo que $42 \%$ acreditaram que Goulart estaria levando o Brasil para o comunismo e $25 \%$ apontaram a suposta intenção de fechar o Congresso. Os resultados da classe $\mathrm{C}$ foram semelhantes ao resultado geral, porém, na classe $\mathrm{D}$, os números mostram o segmento social menos empolgado com a nova situação política. No extrato social mais pobre, o número de abstenções foi maior, pois atingiu $42 \%$. Porém, na faixa $\mathrm{D}$, foi maior também a proporção dos que associaram a queda de Goulart às iniciativas de interesse popular (21\%) e menor o número dos que acreditaram no argumento do perigo comunista (19\%). Não obstante, mesmo na classe D, predominou a aceitação dos discursos golpistas, pois a soma das opções 1 e 3 totalizou 37\% das preferências (os $19 \%$ já citados mais $18 \%$ que optaram pelo argumento de que Goulart iria fechar o Congresso).

Para encerrar a análise dos resultados da pesquisa realizada entre 12 e 22 de maio de 1964 em São Paulo, vale a pena mencionar algumas tabelas que indicam apoio a certas ações da ditadura, inclusive os expurgos. Nos registros, constata-se, com consternação, que a maioria dos entrevistados concordou com as punições políticas, principalmente se os alvos fossem de esquerda. O IBOPE perguntou se a cassação dos mandatos dos parlamentares comunistas tinha sido uma medida acertada. A resposta: $74 \%$ disseram que sim contra apenas $12 \%$ que condenaram o expurgo. A pergunta seguinte foi sobre a prisão de líderes sindicais ligados aos comunistas. Os entrevistados paulistanos responderam majoritariamente a favor $(72 \%)$, contra apenas $12 \%$ contrários às prisões. 
Outra pesquisa realizada em São Paulo alguns dias depois, na última semana de maio, explorou novamente o apoio à repressão política. Dessa vez, foi perguntado aos paulistanos se eram a favor ou contra as cassações em geral, certamente para fazer uma diferenciação face à pesquisa anterior, que perguntou somente sobre o expurgo de comunistas. O apoio às "cassações em geral" foi menor do que o apoio ao expurgo de comunistas, mas, ainda assim, era elevado: $57 \%$ manifestaram-se a favor, $15 \%$ eram contra e $28 \%$ se abstiveram. Atenção ao detalhe significativo: o apoio aos expurgos alcançava a maioria, porém, quando se falava no expurgo de comunistas, essa proporção se elevava ainda mais.

\section{Os vitoriosos lançaram uma campanha discursiva para convencer que sua ação foi necessária no interesse da maioria}

Resultados de outras pesquisas confirmam a boa disposição de parte do eleitorado em relação ao governo que emergiu do golpe, inclusive enquetes realizadas na Guanabara. O mais impactante é a revelação do apoio dos cariocas às políticas de expurgo iniciais da ditadura, de modo semelhante ao que se constatou em São Paulo. Na última semana de maio de 1964, o IBOPE ouviu 511 entrevistados na Guanabara, aplicando questões para dimensionar a opinião sobre o novo regime. Uma delas perguntou: "pelas medidas tomadas no campo econômico-financeiro, que acha do governo Castelo Branco"? Os entrevistados responderam da seguinte maneira: $51 \%$ optaram por bom ou ótimo, $6 \%$ mau ou péssimo e $21 \%$ regular. Para avaliar a opinião sobre os expurgos, perguntou-se o que achavam da "cassação de mandatos e suspensão de direitos políticos de maneira geral". A resposta favorável foi de $56 \%$, enquanto apenas $21 \%$ dos entrevistados disseram ser contra as cassações. ${ }^{11}$

Uma das perguntas aplicadas nessa pesquisa e que apareceu também em enquete realizada em São Paulo explorou a opinião sobre a motivação dos expurgos (Tabela 10).

Constata-se a adesão da maioria aos discursos favoráveis ao golpe, aceitando o argumento de que as cassações visaram os inimigos apontados pelos golpistas: comunistas, subversivos e corruptos. A última opção da enquete, que atraiu $28 \%$ das respostas, provavelmente buscava atender aos entrevistados que não apoiavam os expurgos, pois explicava as punições pelo motivo de "perseguições políticas". Era uma sugestão de que o processo de expurgo fora ilegítimo e não conforme os argumentos apresentados pelo governo, ou seja,

"O IBOPE perguntou especificamente sobre a cassação do ex-presidente Juscelino Kubitschek, e o resultado foi bem diferente: $45 \%$ foram contra e apenas $25 \%$ a favor. Apesar do fraco apoio popular à medida, o governo militar cassou JK poucos dias depois da pesquisa. 
Tabela 10. Pesquisa do Instituto Brasileiro de Opinião Pública e Estatística (IBOPE) realizada na última semana de maio de 1964, na Guanabara, com base em 511 entrevistas

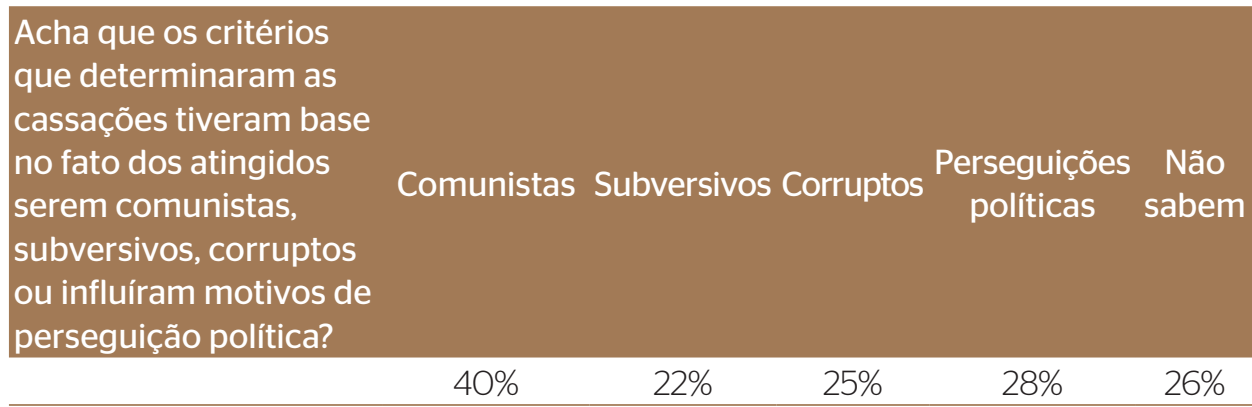

Fonte: Arquivo Edgard Leuenroth.

Obs: Os pesquisadores incluíram uma nota metodológica para explicar por que a soma das respostas superou os 100\% - a razão é que se permitiu aos entrevistados escolherem mais de uma opção.

tratar-se-ia de perseguições políticas movidas por outros objetivos que não a caça a comunistas, subversivos e corruptos. Nos resultados dessa enquete, nota-se, mais uma vez, a proeminência da temática anticomunista, embora o IBOPE tenha oferecido também a resposta "subversivos" - uma definição mais vaga para as esquerdas. Dessa feita, também, o anticomunismo sensibilizou em proporção ainda maior as camadas sociais privilegiadas: na chamada classe A-B, a opção "comunistas" teve $50 \%$ das preferências, enquanto, na classe D, apenas $25 \%$ acharam que a motivação das punições era atingir os comunistas.

Em São Paulo, foi aplicada a mesma pergunta, em pesquisa realizada também na última semana de maio, com resultados semelhantes aos do Rio: a opção "comunistas" alcançou 27\%; a resposta "subversivos" atingiu 14\%; a opção "corruptos" teve 16\%; enquanto "perseguições políticas" atingiu $19 \%$. Em São Paulo, igualmente, os argumentos anticomunistas sensibilizaram de maneira mais intensa a classe A-B, em que a opção "comunistas" alcançou 40\% (e apenas $16 \%$ na classe D).

Há mais uma pesquisa que revela a adesão às políticas de expurgo da ditadura e a simpatia que o governo Castelo Branco gozou no período inicial (um tanto efêmera, como se verá). A enquete foi aplicada na Guanabara entre 24 e 29 de junho de 1964 e uma das perguntas, nada ingênua, foi: "se Castelo Branco fizer um bom governo o Sr. (a) aceitaria que ele continuasse governando, mesmo sem eleições?" O plano de prorrogar o mandato do general já estava em negociação nos corredores do poder e a pesquisa provavelmente foi encomendada para sondar como seria recebido na opinião pública. A resposta deve ter animado os defensores da ideia, afinal aprovada pelo Congresso na segunda semana de julho. Na pesquisa de fim de junho de 1964, $62 \%$ dos cariocas responderam que aceitariam Castelo Branco governando depois do fim do mandato "legal" ${ }^{12}$ contra $28 \%$ contrários e $10 \%$ de abstenções.

\footnotetext{
${ }^{12}$ Após ter sido empossado na presidência em decorrência do golpe, por meio de eleição indireta no Congresso, o entendimento dominante era que Castelo Branco deveria terminar o mandato constitucional de Goulart. O mandato que terminaria em 31 de janeiro de 1966 foi estendido até 15 de março de 1967.
} 
Na mesma pesquisa, foi aplicada uma questão para avaliar a disposição do eleitorado carioca em relação à demanda por anistia para os perseguidos políticos. O resultado mostra que a opinião favorável aos expurgos ainda era forte (Tabela 11).

Mais uma vez, os pesquisadores resolveram testar o ânimo dos eleitores, especificamente em relação aos comunistas, distinguindo-os dos outros cassados. O resultado mostra o apoio às políticas repressivas da ditadura, já que a maioria era contra uma anistia geral (para os "outros cassados", ou seja, os que não eram comunistas) na proporção de $44 \%$ contra $36 \%$ favoráveis ao perdão. O apoio ao expurgo anticomunista era consideravelmente mais elevado, já que apenas $14 \%$ consideraram a anistia para os comunistas uma boa medida, enquanto 63\% achavam má ideia cancelar a punição aos "vermelhos".

Enfim, as pesquisas apontam a existência de apoio na opinião pública para as políticas de expurgo da ditadura, notadamente quando elas atingiam os ativistas de esquerda e também revelam a boa aceitação do governo Castelo Branco nos primeiros meses. Porém, nem tudo eram flores para os militares e aliados civis que tomaram o poder em 1964. As enquetes mostram que a boa vontade em relação aos novos governantes poderia ser efêmera, pois, já em 1965, a "opinião" estava impaciente e avaliando negativamente o governo Castelo Branco. Além disso, mesmo nas pesquisas realizadas logo após o golpe, as respostas a algumas perguntas mostram que o apoio aos projetos autoritários tinha limites. Vejamos na Tabela 12.

As pesquisas foram realizadas separadamente nas duas cidades, porém na mesma semana e com as mesmas perguntas; foram agrupadas aqui para facilitar a visualização. Interessante como os resultados são convergentes nas duas metrópoles, o que ocorreu também em pesquisas analisadas anteriormente. O significado político que pode ser extraído da pesquisa é importante. Muita gente apoiou o golpe e também os expurgos políticos, demonstrando aceitar atentados contra a Constituição e desrespeito aos direitos fundamentais. No entanto, a grande maioria preferia manter o direito à escolha direta dos governantes, o que implicava limite à aceitação de uma ditadura clássica.

Na mesma linha, a pesquisa realizada na Guanabara entre 24 e 29 de junho de 1964 apresentou um dado significativo. Nessa enquete, como já apontado, o estado de espírito dos cariocas era bem favorável ao primeiro governo militar, pois a maioria recusou a anistia e respondeu favoravelmente à proposta de extensão do mandato de Castelo Branco. No entanto, quando perguntados se, em princípio, o próximo presidente deveria ser um civil ou militar, os entrevistados responderam assim: 59\% preferiam que o sucessor de Castelo Branco fosse um civil contra apenas $16 \%$ favoráveis a um sucessor militar (e $25 \%$ de abstenções).

Os dados permitem a seguinte interpretação: mesmo que o golpe e os expurgos tenham alcançado a aceitação da maioria, isso não implicava apoio em igual proporção ao estabelecimento de uma ditadura. Em outras palavras, pode ter havido apoio a ações autoritárias, mas não necessariamente suporte da maioria da sociedade para implantação de uma ditadura tutelada pelos 
Tabela 11. Pesquisa do Instituto Brasileiro de Opinião Pública e Estatística (IBOPE) realizada entre 24 e 29 de junho de 1964, na Guanabara, com base em 500 entrevistas

\begin{tabular}{lccc|}
\hline $\begin{array}{l}\text { O sr. (a) consideraria uma boa ou má medida o } \\
\text { governo atual decretar uma anistia antes das } \\
\text { eleições de 1965? }\end{array}$ & $\begin{array}{c}\text { Uma boa } \\
\text { medida }\end{array}$ & $\begin{array}{c}\text { Uma má } \\
\text { medida }\end{array}$ & $\begin{array}{c}\text { Não } \\
\text { opinam }\end{array}$ \\
\hline Para os comunistas & $14 \%$ & $63 \%$ & $23 \%$ \\
\hline Para os outros cassados & $36 \%$ & $44 \%$ & $20 \%$ \\
\hline
\end{tabular}

Fonte: Arquivo Edgard Leuenroth.

Tabela 12. Pesquisas do Instituto Brasileiro de Opinião Pública e Estatística (IBOPE) realizadas na última semana de maio de 1964, na Guanabara (511 entrevistados) e em São Paulo (519 entrevistados)

\begin{tabular}{lccc}
$\begin{array}{l}\text { Em sua opinião, qual a melhor forma para } \\
\text { eleger-se o Presidente da República? }\end{array}$ & $\begin{array}{c}\text { Eleição } \\
\text { direta }\end{array}$ & $\begin{array}{c}\text { Eleição } \\
\text { indireta }\end{array}$ & $\begin{array}{c}\text { Não sabe } \\
\text { Guanabara }\end{array}$ \\
\hline $\begin{array}{l}80 \% \\
\text { São Paulo }\end{array}$ & $77 \%$ & $12 \%$ & $9 \%$ \\
\hline
\end{tabular}

Fonte: Arquivo Edgard Leuenroth.

militares. As pesquisas sugerem que o apoio social a projeto autoritário duradouro era instável e que não seria trabalho simples conquistar legitimidade e estabilidade política para uma ditadura.

Os desafios enfrentados pelos líderes da ditadura apareceram de maneira mais aguda poucos meses depois, em 1965, em pesquisa que mostra queda drástica de popularidade do primeiro governo militar entre eleitores da Guanabara. Na pesquisa da última semana de maio de 1964, 51\% dos cariocas avaliaram o governo Castelo Branco como ótimo ou bom (considerando a política econômica) contra apenas $6 \%$ que responderam mau ou péssimo e $21 \%$ que acharam regular. Porém, a enquete realizada entre 5 e 13 de fevereiro de 1965 mostrou importante mudança no ânimo político dos cariocas. A expectativa positiva e o otimismo inicialmente dirigido à ditadura haviam passado, conforme se vê nos dados das Tabelas 13 e 14.

O resultado confirma versões sobre a impopularidade do governo Castelo Branco ao final do seu mandato, o que teria levado o segundo presidente militar, Costa e Silva, a elaborar estratégias para recuperar o prestígio do regime autoritário. ${ }^{13}$ No caso da primeira pergunta, a esmagadora maioria das respostas (73\%) apontou piora da situação econômica na comparação entre o primeiro ano do governo militar (1964) e o último ano de Goulart (1963), uma evidência de que a política recessiva aplicada pelos novos gestores da economia causou estragos. ${ }^{14}$ A pergunta seguinte mostrou resultado melhor para

\footnotetext{
${ }^{13} \mathrm{~A}$ impopularidade de Castelo Branco devido à sua política econômica - inclusive entre grupos que haviam apoiado o golpe - foi notada por vários autores, entre eles, Lira Neto, Castelo: a marcha para a ditadura, São Paulo, Contexto, 2004

${ }^{14}$ Sobre os resultados da política econômica, ver Francisco Vidal Luna; Herbert Klein, "Transformações econômicas no período militar (1964-1985)", In: Daniel Aarão Reis Filho; Marcelo Ridenti; Rodrigo Patto Sá Motta (orgs.), A ditadura que mudou o Brasil: 50 anos do golpe de 1964, Rio de Janeiro, Zahar, 2014, p. 92-111.
} 
Tabela 13. Pesquisa do Instituto Brasileiro de Opinião Pública e Estatística (IBOPE) realizada entre 5 e 13 de fevereiro de 1965 na Guanabara (505 entrevistados)

\begin{tabular}{lcccc}
$\begin{array}{l}\text { O sr. (a) acha que a situação } \\
\text { econômica do país, durante o ano } \\
\text { passado, melhorou ou piorou, em } \\
\text { comparação com o ano anterior? }\end{array}$ & Melhorou & Piorou & Igual & $\begin{array}{c}\text { Não } \\
\text { opinaram }\end{array}$ \\
\hline & $16 \%$ & $73 \%$ & $6 \%$ & $5 \%$ \\
\hline
\end{tabular}

Fonte: Arquivo Edgard Leuenroth.

Tabela 14. Pesquisa do Instituto Brasileiro de Opinião Pública e Estatística (IBOPE) realizada entre 5 e 13 de fevereiro de 1965 na Guanabara (505 entrevistados)

\begin{tabular}{lrcc}
$\begin{array}{l}\text { De uma maneira geral o sr (a) está satisfeito } \\
\text { ou insatisfeito com o governo do Presidente } \\
\text { Castelo Branco? }\end{array}$ & Satisfeito & $\begin{array}{c}\text { Não } \\
\text { Insatisfeito }\end{array}$ & $\begin{array}{c}45 \% \\
\text { opinaram }\end{array}$ \\
\hline
\end{tabular}

Fonte: Arquivo Edgard Leuenroth.

o governo Castelo Branco, mas ainda ruim no contraste com a situação do ano anterior: $46 \%$ de cidadãos cariocas insatisfeitos contra $45 \%$ de satisfeitos. Comparando-se as duas pesquisas, o número de insatisfeitos com Castelo Branco era menor do que o número daqueles que perceberam piora na situação econômica. Uma explicação possível é que parte dos eleitores infelizes com o desempenho econômico poderia estar contente com outras coisas ou talvez atribuísse parte da culpa ao legado do governo Goulart.

A insatisfação com o governo Castelo Branco se confirmou nas respostas a outra pergunta, que mediu o apoio popular para eventual nova prorrogação do mandato do general. Em junho de 1964, como foi mostrado anteriormente, $62 \%$ dos cariocas se disseram a favor da continuação do ditador após o fim do seu mandato legal. Em fevereiro de 1965, a opinião havia mudado drasticamente, conforme puderam observar os pesquisadores do IBOPE, pois $75 \%$ dos entrevistados preferiam mudança no comando do país (Tabela 15).

\section{Considerações finais}

Nos idos de 1964, a crise política foi resolvida pelas armas ou pelo uso potencial da força militar, já que, apesar da mobilização de tropas, o esperado confronto bélico não ocorreu. ${ }^{15}$ Para a decisão de colocar as tropas em movimento, os golpistas não precisavam consultar a opinião dos cidadãos. Considerando-se também as outras razões já apontadas na linha do ceticismo, isso não diminuiria a validade das enquetes de opinião?

${ }^{15} \mathrm{O}$ que não significou ausência de violência, já que houve mortos e torturados nos dias do golpe. 
Tabela 15. Pesquisa do Instituto Brasileiro de Opinião Pública e Estatística (IBOPE) realizada entre 5 e 13 de fevereiro de 1965 na Guanabara (505 entrevistados)

\begin{tabular}{|c|c|c|}
\hline $\begin{array}{l}\text { Na sua opinião a eleição para Presidente da } \\
\text { República deve ser realizada em } 1966 \text { como foi } \\
\text { marcada, ou considera que o mandato do Presidente } \\
\text { Castelo Branco deve ser mais uma vez prorrogado? }\end{array}$ & ${ }_{1966}^{E m}$ Prorrogado & $\begin{array}{c}\text { Não } \\
\text { opinaram }\end{array}$ \\
\hline & $75 \%$ & $13 \%$ \\
\hline
\end{tabular}

Fonte: Arquivo Edgard Leuenroth.

Embora existam motivos para questionar a utilidade das pesquisas, penso haver razões mais sólidas para crer em sua relevância. A "opinião" era elemento importante para os agentes políticos e para o Estado - todos estavam atentos a ela na busca pela conquista e manutenção do poder. A decisão de deslanchar o golpe foi influenciada pela sensação de que teria apoio em segmentos sociais expressivos. A ditadura instalou-se graças à força militar, mas, para durar e ter estabilidade política, era preciso conquistar legitimidade. Quanto à confiabilidade dos dados do IBOPE, a análise das enquetes, em especial quando comparamos os resultados de diferentes cidades e também levando em conta outras evidências do apoio ao golpe, como o grande número de "marchas" favoráveis aos golpistas e o grande público que elas atraíram, ${ }^{16}$ revela que os resultados das pesquisas constituem elementos muito úteis para a historiografia da ditadura.

Os dados indicam apoio de pouco mais da metade da população (de São Paulo e Rio de Janeiro) ao golpe, confirmando a existência de polarização política no contexto de 1964. Fica evidenciada a influência das mobilizações de direita no período final do governo Goulart, as quais convenceram muitas pessoas do surgimento de grave ameaça à ordem. Significativamente, as pesquisas mostram que as camadas sociais de renda mais alta receberam com mais entusiasmo o golpe, sendo também os grupos mais sensíveis às representações sobre o "perigo vermelho".

No entanto, é fundamental lembrar que a outra metade dos cidadãos não apoiou o golpe ou mostrou-se indecisa/indiferente em relação à queda de Goulart. As pesquisas disponíveis não permitem saber com certeza se o apoio majoritário surgiu antes ou depois do golpe. A maioria bem disposta em relação ao golpe registrada nas enquetes de maio de 1964 pode ter surgido não antes do evento, mas depois do sucesso da ação militar, por influência do fato consumado ou dos discursos dos vitoriosos que tomaram conta do espaço público.

Merece destaque o papel ocupado pela opinião anticomunista. Os dados revelam elevada percepção sobre a presença comunista no contexto do governo Goulart, o que a maioria considerava uma ameaça e um mal. Difícil saber o que "comunismo" significava para essas pessoas, mas, certamente, não o

\footnotetext{
${ }^{16}$ Sobre o tema das "marchas", cf. Aline Presot, "Celebrando a 'Revolução': as Marchas da Família com Deus pela Liberdade e o Golpe de 1964", In: Denise Rollemberg; Samantha Quadrat, A construção social dos regimes autoritários. Legitimidade, consenso e consentimento no século XX. Rio de Janeiro, Civilização Brasileira, 2010, p. 71-96.
} 
confundiam simplesmente com o projeto de reformas de base, que tinha grande aceitação - exceto o voto para os analfabetos, que poderia ser conectado ao aumento potencial da força da esquerda. Parece claro que o grande temor não eram as reformas, tampouco uma indisposição inata contra João Goulart, que, em algumas pesquisas próximas ao golpe, apareceu com apoio popular. O grande medo foi provocado pela sensação de existência de ameaças radicais à ordem social e política, temor que foi verbalizado em linguagem anticomunista. Goulart perdeu legitimidade aos olhos de muitos cidadãos quando a sua imagem foi associada a esse "perigo", que parece ter estimulado a maioria a apoiar o expurgo político. Significativamente, o apoio aos expurgos (prisões, cassações) era maior quando os alvos anunciados eram os "comunistas".

\section{Pode ter havido apoio a ações autoritárias, mas não necessariamente suporte da maioria da sociedade para implantação de uma ditadura tutelada pelos militares}

É importante perceber que o sentimento anticomunista não era absurdo ou mera manipulação, pois as esquerdas tinham força crescente e buscavam aumentar sua influência no governo Goulart. Esse movimento analítico é necessário para compreender melhor o contexto e as escolhas dos grupos de direita, afinal, a política é um jogo com pelo menos dois contendores. As estratégias dos atores são influenciadas pela percepção que têm sobre os planos e a força de seus adversários, mesmo quando são distorcidos e exagerados. No entanto, a análise de que a motivação golpista principal era combater as esquerdas não pode servir de justificativa para as ações autoritárias. Nessa linha, poderíamos chegar ao argumento absurdo de que o golpe foi culpa da esquerda. Argumento torto, que violenta a lógica. Culpáveis são os grupos que perpetraram o golpe e não os seus alvos.

Além disso, mesmo se hipoteticamente aceitássemos o ponto de vista de quem lutava contra a esquerda, o golpe não era a única opção na luta pela ordem. Poderiam ter defendido seus interesses e ideais utilizando instituições e instrumentos compatíveis com a democracia liberal. Sobretudo, a defesa da ordem não implicava necessariamente uma ditadura, tampouco lançar mão da tortura e dos desaparecimentos como política de Estado. A propósito, vale a pena lembrar os casos italiano e alemão nos anos 1970, em que o Estado enfrentou o desafio armado da extrema-esquerda sem ditadura e sem desaparecimentos.

As pesquisas de opinião apontam que segmentos sociais expressivos receberam bem o golpe e deram sustentação aos expurgos, mostrando pouco apreço pelas instituições e pelos direitos civis. Para tais setores, certamente, o novo regime foi considerado legítimo ou, ao menos, aceitável. As enquetes ajudam a entender por que parte da sociedade apoiou inicialmente a ditadura, explicação que passa inexoravelmente pelo medo de ameaças à ordem. No entanto, há que estudar essas estratégias de legitimação sem esquecer que nem todos 
apoiaram. É necessário aprofundar as pesquisas sobre o ativismo contrário à ditadura, sem aceitar as mitologias da resistência, que se prestam a muitas manipulações. Do mesmo modo, deve-se atentar para os indiferentes e para os que adotaram estratégias de acomodação com o Estado autoritário. ${ }^{17}$

A questão do apoio social à ditadura deve ser estudada em dimensão temporal, observando-se as mudanças que ocorreram com o passar dos anos, e foram vinte anos de regime autoritário. As enquetes mostram apoio inicial ao golpe e ao expurgo, mas também a preferência por civis no poder e desejo de eleger o presidente por votação direta. Havia adesão a medidas autoritárias, mas não necessariamente a uma ditadura liderada pelos militares. Talvez seja essa uma das razões por que a ditadura preferiu fazer concessões à cultura liberal, mantendo parlamentos abertos, eleições etc. Do mesmo modo, residiria aí uma explicação para o cuidado constante dos líderes da ditadura em negarem o caráter ditatorial do Estado, sempre fazendo loas à democracia $\mathrm{e}$ prometendo seu pleno restabelecimento. As pesquisas indicam que os líderes podem ter agido assim porque haveria pouca aceitação para uma ditadura "pura" e sem ambiguidades.

Além da preferência por civis no comando e por eleições diretas, as enquetes mostram a rápida erosão do apoio ao governo Castelo Branco. Nessas condições, em que a opinião política flutuou ao sabor das conjunturas, é difícil falar em consenso autoritário ou em apoio consensual à ditadura, no sentido de apoio majoritário. Uma formulação nesses termos é pouco convincente, salvo se ajustarmos o argumento para a existência de virtual consenso anticomunista, que implicava apoio majoritário a medidas autoritárias quando a sensação de ameaça à ordem tornava-se aguda.

De qualquer modo, há necessidade de procurar mais evidências e aprofundar a análise. Nessa linha, seria importante encontrar pesquisas referentes aos períodos seguintes, para medir o estado de espírito da opinião em momentoschave como os protestos de 1968, quando o apoio ao governo caiu muito, ou no período do "milagre econômico", que atuou em direção contrária, ou seja, elevando a sensação de legitimidade. ${ }^{18}$

Enfim, a opinião em relação à ditadura e o apoio a ela mudaram ao longo do tempo e não parece que o regime autoritário encontrou sustentação na maioria da população por todo o período. Afinal, se houvesse apoio majoritário e consenso da população, por que a necessidade de recorrer a constantes medidas autoritárias? Na combinação entre legitimidade e coerção, que fundamenta o poder de qualquer Estado, os dois lados da balança mudaram de posição ao longo daqueles vinte anos. O desafio é compreender melhor o peso relativo ocupado por cada elemento na sustentação da longa ditadura brasileira.

\footnotetext{
${ }^{17} \mathrm{Cf}$. Rodrigo Patto Sá Motta, As universidades e o regime militar, Rio de Janeiro, Zahar, 2014.

${ }^{18}$ Para a popularidade do governo Médici, ver Janaina Cordeiro, Lembrar o passado, festejar o presente: as comemorações do sesquicentenário da Independência entre consenso e consentimento. Tese de doutorado, Universidade Federal Fluminense, Niterói, 2012.
} 